\title{
Epidemiology and Determinants of Knowledge, Attitude and Practice of Preventing COVID-19 Positive Patients at Southern Tigray Ethiopia: A Facility Based Cross-Sectional Study.
}

Abdukadir Nigus Mohammed ( $\sim$ abdukadirnigus@gmail.com )

Alamata General Hospital https://orcid.org/0000-0002-0351-1143

Reda Haddish Berhe

Lemlem Karl Hospital

Said Mussa Said

Mekelle University College: Mekelle University

\section{Research}

Keywords: Attitude, COVID-19, knowledge, practice, Southern Tigray Ethiopia

Posted Date: July 1st, 2021

DOl: https://doi.org/10.21203/rs.3.rs-649827/v1

License: (c) (1) This work is licensed under a Creative Commons Attribution 4.0 International License.

Read Full License 


\section{Abstract}

Background: The novel corona virus is a serious health problem world widely and is spreading in an immune naive population. Deaths are rising sharply, and health systems are under strain. There are confirmed cases of the virus in Ethiopia that found to have the problem. Therefore, the present study intended to assess epidemiology and determinant of knowledge, attitude, and practice of preventing COVID-19 positive patients at Southern Tigray Ethiopia.

Methods: A facility based cross-sectional study was conducted from August 6, to October 26, 2020 in selected health care facilities of south Tigray. Multi-stage sampling technique was employed. Descriptive statistics were employed to describe the characteristics of the cross-section and to estimate the prevalence of clients having knowledge, attitude and practice of prevention. Bivariate analysis was performed using binary logistic regression.

Results: A total of 170 COVID-19 positive patients were involved and eligible on the survey with the response rate of $98 \%$. Of these participants, $106(62.4 \%)$ were male. Over half $(51.2 \%)$ of the COVID-19 positive patients had good knowledge on transmission of COVID-19; about $64.4 \%$ had more accurate knowledge on prevention; ; about $62.9 \%$ had more positive attitude on prevention; and about half, $47.1 \%$ had poor practices of the precautionary measures against COVID-19. Participants who had more accurate knowledge for preventing COVID-19and more positive attitude of preventing COVID-19were 95\%times $(A O R=0.05,95 \% \mathrm{Cl}=0.012-0.18)$ and $68 \%(A O R=0.32,95 \% \mathrm{Cl}=0.1-1.02)$ less likely, respectively, to implement the precautionary measures of COVID-19.

Conclusion: Our findings suggest the need for effective and tailored health education programs aimed at improving COVID-19 knowledge, thereby leading to more favorable attitudes and to implementation and maintenance of safe practices.

\section{Background}

The novel coronavirus is a serious health problem world widely and is spreading in an immune naive population. Deaths are rising sharply, and health systems are under strain.The first cases of novel coronavirus were reported by the World Health Organization (WHO), on 31 December 2019, when a few patients were diagnosed with pneumonia in the city of Wuhan in China [1, 2].

In Africa, over 2,134,290 cases and 51,033 deaths were reported until 27 November 2020 [3]. In Ethiopiaalso,253,120 total cases and 3,570 deaths in the country until 27 April 2021. There are confirmed cases of the virus in Ethiopia that found to have the problem while being treated for other medical problem. Individuals who neither have contact nor travel history were found to have the problem. This cautions the spread of the virus to the community [4].

Worldwide, the major challenges lie in delivering proper care to COVID-19 patients and to prevent the spread of infection among healthcare personnel and the general public. The proper preventive measures 
for COVID-19 infection have not been effectively implemented in all places and adherence to them is not consistent [5-7]. Additionally, the implementation of new guidelines brings its own set of challenges related to the communication of the guidelines, availability of resources, access to equipment, and the practice of use of equipment, simulation sessions and desire to participate [8].

In order to declare and install effective prevention strategies, having knowledge about basic hygiene principles and modes of disease transmission, and measures in such an environment is, therefore, of vitally importance. To achieve an ultimate success against the ongoing encounter against COVID-19 in Ethiopia, people's commitment to these control measures is necessary $[9,10]$. Health system of Ethiopia is not as developed as other countries so if the virus is not contained it will cost the country many things. Knowledge, attitude, and practice (KAP) investigation are important to collect information on what is known, believed, and done by a specific population; But in Ethiopia those types of research is not available like other countries. Therefore, the present study intended to assessepidemiology and determinant ofknowledge, attitude, and practice of preventing COVID-19 positive patients at Southern Tigray Ethiopia.

\section{Methods}

\section{Study design and setting}

A facility based cross-sectional study was conducted from August 6, to October 26, 2020 in selected health care facilities of south Tigray which is located approximately $660 \mathrm{~km}$ away from Addis Ababa, Ethiopia. In this zone there are 3 general hospitals, 6 primary hospitals, 5 health centers and around 25 health posts with 1582 health care workers. All patients and their attendants in southern Tigray treatment center were considered as source population and the study population was selected patients and attendants in southern Tigray treatment center who fulfilled the inclusion criteria.Health care workers and hospital and unit manager who avail during the data collection periodwere included. All clients who avail during data collection period within the southern Tigray treatment center were included. However, clients who were mentally incompetent or critically ill or unable to give information during data collection were excluded from the study.

\section{Sample size and sampling procedure}

In order to have representative respondents from the urban and rural districts, multi-stage sampling technique was used; after the proportional allocation to each Wereda or town, respondents were selected using Random sampling method to identify the study participants.

\section{Variables and source of data}

The data was collected for the large-scale COVID-19 screening in southern Tigray Ethiopia treatment center. The main outcome variable was COVID-19 positive client's having knowledge, attitude, and practice on prevention of coronavirus. Predictor variables considered were socio-demographic 
characteristics, Hospital and individual related factors, Knowledge of clients on COVID-19, Attitude of clients on COVID-19, practice of clients on COVID-19 prevention. We extracted data on these predictor variables from semi-structured questionnaires, register, follow-up forms, and other clinical records. These registers and forms are regularly filled as part of a routine paper-based patient record system. The data were extracted by a trained nurse.

\section{Data Quality Control}

To preserve the quality of the data, training was provided for data collectors on the aim of the study and methods of data collection. A computer-based data collection was used to control entry errors. Field level conquest was done to control the data collection and data quality.

\section{Data processing and analysis}

Data was first checked manually for completeness and then entered into Epi-Info software ver. 3.1. After data entry and cleaning, the data was transferred to STATA software ver.13.for statistical analysis. Descriptive statistics were employed to describe the characteristics of the cross-section and to estimate the prevalence of clients having knowledge, attitude and practice of prevention. Bivariate analysis was performed using binary logistic regression. Variables which showed significant association in the bivariate analyses (P-value $<0.25$ ) were candidates for the multivariate logistic regression model. To control for the effect of confounding variables, multivariate logistic regressions adjustments were used. Explanatory variables significantly associated with the outcome variable with $p$-value $<0.05$ in multivariate logistic regression were determined as independent predictors.

\section{Results}

\section{Socio-demographic characteristics}

A total of 170 COVID-19 positive patients were involved and eligible on the survey with the response rate of $98 \%$. Of these participants, $106(62.4 \%)$ were male. At the time of enrollment to treatment center, there were $150(88.2 \%)$ patients at the age of 18-44 years. Majority of a patient were placed on Alamata and Maichew respectively. Most of the patients (42.4\%) had an income of $3001-10,000$ ETB. The popular of COVID-19 positive patients had education qualification diploma and degree respectively. The predominant of COVID-19 positive patients (87.1\%) had religion of orthodox. Health care professionals were the popularoccupation of COVID-19 positive patients (40\%).

\section{Determining experience of COVID -19 related illness}

The experiences of COVID-19 related illness and its predictors were assessed. Among the study participants, $7.3 \%$ had a history of fever and an experience of respiratory illness before the study. Of those who had an experience of respiratory illness, $7.1 \%$ had a cough, $5.9 \%$ had pain, $2.9 \%$ had a sore throat, $6.5 \%$, had shortness of breath, $5.3 \%$, had generalized body weakness, $8.8 \%$, had under line comorbidity and conditions. 


\section{Epidemiology of knowledge, attitude and practice (KAP) for the prevention of COVID-19}

Findings demonstrated that COVID-19 positive patients had knowledge on transmission modes, prevention methods, attitude and practice for prevention of COVID-19. Over half (51.2\%) of the COVID-19 positive patients had good knowledge on transmission of COVID-19; about $64.4 \%$ had more accurate knowledge on prevention; ; about $62.9 \%$ had more positive attitude on prevention; and about half, $47.1 \%$ had poor practices of the precautionary measures against COVID-19 (Fig 1).

\section{Determinants factors associated with Knowledge of preventing COVID-19 positive patient}

Based on the results of bivariate logistic regression analysis shown in Table-3, variables which showed significant association with knowledge of preventing COVID-19 positive patient at 5\% significant level were selected for multivariate analysis. In multivariate logistic regression result, odds ratio is the estimated multiplicative change in the odds for a unit change in the predictor variables, controlling for the effects of other predictors.

The significant predictors of knowledge of preventing COVID-19 positive patient at $5 \%$ significant level after controlling for the effects of others predictors were; income, occupation, knowledge of transmission COVID-19, underline co-morbidity and conditions (Table-3).

Hence, those who had good knowledge of transmission were $94 \%$ times $(A O R=0.06,95 \% \mathrm{Cl}=0.018-$ 0.19) less likely to be knowledgeable about the prevention methods of COVID-19 than those who did not hadknowledge of transmission. Regarding the occupation of respondents, health workers were $99.4 \%$ times less likely, to be knowledgeable on the prevention methods of COVID-19 than other occupants (Table-3).Those participants who under line co-morbidity and conditions were $94 \%$ times (AOR=0.6, 95\% $\mathrm{Cl}=0.006-0.065)$ less likely to be knowledgeable about the prevention methods of COVID-19 than those who did not(Table-3).

\section{Determinants factors associated with attitude of preventing COVID-19 positive patient}

The significant predictors of attitude of preventing COVID-19 positive patient at $5 \%$ significant level after controlling for the effects of others predictors were; knowledge of transmission COVID-19, wash hands and face after coming outsides, treated at home,use a facemask in crowded place(Table-4).

Hence, those who had good knowledge of transmission were 95\% times (AOR=0.05, 95\% Cl $=0.016-$ 0.17) less likely to have an attitude about the prevention methods of COVID-19 than those who did not hadan attitude of prevention.In addition to those whoagreewashing hands and face after coming outsides were $79 \%$ times less likely to have an attitude on the prevention methods of COVID-19 than those who did not hadan attitude of prevention. Thoseparticipants who agree treated at homewere $90 \%$ times (AOR=0.1, 95\% Cl $=0.028-0.32)$ less likely to have an attitude on the prevention methods of COVID-19 than those who did not hadan attitude of prevention. Furthermore, those participants who were agree touse facemask in crowded place were $98.4 \%$ times ( $A O R=0.016,95 \% \mathrm{Cl}=0.001-0.3$ ) less likely to 
have an attitude on the prevention methods of COVID-19 than those who did not hadan attitude of prevention(Table-4).

\section{Determinants factors associated with practice of preventing COVID-19 positive patient}

The significant predictors of practice of preventing COVID-19 positive patient at $5 \%$ significant level after controlling for the effects of others predictors were; Experience of respiratory illness, Knowledge for preventing COVID-19, Attitude of transmission COVID-19, Maintain social distance, Obeying governmental rules related to COVID-19, Maintain a healthy lifestyle focusing on outbreak, Use tissues or hanker chips during coughing/sneezing(Table-5).

Hence, those who had Experience of respiratory illnesswere $96 \%$ times (AOR $=0.04,95 \% \mathrm{Cl}=0.007-0.27$ ) less likely to implement the precautionary measures of COVID-19.Participantswhohadmore accurateknowledge for preventing COVID-19and more positive attitude of preventing COVID-19were $95 \%$ times (AOR=0.05, 95\% Cl $=0.012-0.18)$ and $68 \%(A O R=0.32,95 \% \mathrm{Cl}=0.1-1.02)$ lesslikely, respectively, to implement the precautionary measures of COVID-19. In addition to those who Maintain social distance were $98.3 \%$ times $(\mathrm{AOR}=0.01795 \% \mathrm{Cl}=0.001-0.21$ ) less likely to implement the precautionary measures of COVID-19.Furthermore, those participants who obeying governmental rules related to COVID-19,Maintain a healthy lifestyle focusing on outbreak and Use tissues or hanker chips during coughing/sneezing were $90.5 \%$ times(AOR $=0.009595 \% \mathrm{Cl}=0.009-1.03), 80 \%$ times(AOR $=0.2$ $95 \% \mathrm{Cl}=0.04-1.04)$ and $91 \%$ times $(\mathrm{AOR}=0.0995 \% \mathrm{Cl}=0.008-1.1)$ less likely, respectively,to implement the precautionary measures of COVID-19(Table-5).

\section{Discussion}

The findings reveal a considerable number of socio-demographic factors that affect KAP and should prove valuable when planning health education programs about emerging infectious diseases.

The study found $64.4 \%$ and $51.2 \%$ overall knowledge of the respondents about transmission and prevention of COVID-19, respectively, attitude of the respondents about prevention of COVID-19 was $62.9 \%$. The practice of the prevention of COVID-19 was low (47.1\%).Concerning the determinant factors, income, and occupation, knowledge of transmission COVID-19, underline co-morbidity and conditionswere the factors associated with knowledge on the prevention of COVID-19. Knowledge of transmission COVID-19,wash hands and face after coming outsides, treated at home,use a facemask in crowded placewere significantly associated with attitude on the prevention of COVID-19. The study found that Experience of respiratory illness, Knowledge for preventing COVID-19, Attitude of transmission COVID-19, Maintain social distance, Obeying governmental rules related to COVID-19, Maintain a healthy lifestyle focusing on outbreak, Use tissues or hanker chips during coughing/sneezingwere associated with the practice of precautionary measures against COVID-19.this finding was consistent with crosssectional study done in Bangladesh and Ethiopia [11, 12]. 
This study was conducted three months after the first COVID-19 positive case was reported in the country; thus we expect the study community to have higher awareness now. However, the epidemiology of knowledge was unexpectedly low. The Ethiopian study is compared and contrasted to some others globally. A study conducted in Iran revealed that knowledge about the mode of transmission of the disease found a similar figure of $56 \%$ [13]. In contrast, a study conducted in China revealed that the overall knowledge of COVID-19 was high at 90\% [14]. Our study has found better knowledge on the prevention of COVID-19 than a study conducted in Thailand with a result of, $73.4 \%$ on the knowledge on prevention and control of COVID-19 [15].

The epidemiologyof practices for the prevention of COVID-19 in southern Tigray Ethiopia was 47.1\%, which was lower than the study conducted in Iran, 71\%, [13],but much higher than the study conducted in Thailand, 17\%, [15].

The findings revealed virtually universal agreement among the participants towards reporting to health authorities cases of COVID-19, on the issue wearing a face mask before going to a crowded place, and in following other recommendations. These findings were in line to a very recent study conducted in China; during the rapid rise of COVID-19 outbreak [16]. Saqlain et al. also reported positive attitudes among the vast majority of health care professionals towards wearing protective gear [17]. Similarly, the overall attitude towards actions such wash hands and face after coming from outside and health education can play an important role for COVID-19 prevention was universally favorable. Like in this study, Saqlain et al reported that more than $80 \%$ participants strongly agreed that transmission of COVID-19 could be prevented by following universal precautions given by WHO or CDC [18].

Being a health professional was associated with less accurateknowledge about COVID-19. This finding is supported by the study conducted in Iran [19]. The strength of this study was large and had a broad scope with several strengths. It was based on a randomization sample size and focused on participants from areas that were likely to be high risk; therefore, the findings can be generalized across the city's population. This study has some limitations that are shared with most studies. The cross-sectional nature of the study design limited to include other associated determinant factors that may influence the risk of co-morbidity and mortality inCOVID-19 positive patients. We use dalimited number of questions to measure the epidemiology of knowledge, attitude, and practice. Thus, additional assessments would be important, using all aspects of KAP towards COVID-19, to determine the actual extent of KAP in the general population. Additionally, the unstandardized and inadequate assessment of attitudes and practices towards COVID should be developed via focus group discussion and in-depth interviews and constructed as multi-dimensional measures.

\section{Conclusion}

The study revealed that respondents had moderate knowledge, attitude about preventions mechanisms and practice on the prevention of COVID-19 areas of high risk in Southern Tigray Ethiopia. Our findings suggest the need for effective and tailored health education programs aimed at improving COVID-19 
knowledge, thereby leading to more favorable attitudes and to implementation and maintenance of safe practices.

\section{Abbreviations}

Cl: Confidence Interval

COVID-19: Corona virus disease 2019

ETB: Ethiopian Birr

KAP: Knowledge, Attitude and Practice

\section{Declarations}

\section{Ethics approval and consent}

Ethical approval was obtained from the institutional review board of Lemlem Karl Hospital. Accordingly, permission letter was secured from medical directors at Lemlem Karl Hospital. All the collected patient information was stored anonymous and data was keptconfidential.

\section{Consent for publication}

Not applicable.

\section{Availability of data and materials}

All data relevant to our findings are contained within the manuscript. Requests for further details on the dataset and queries concerning data sharing shall be arranged based on a reasonable request to abdukadirnigus@gmail.com.

\section{Competing interests}

The authors declare that they have no competing interests.

\section{Funding}

Not applicable.

\section{Authors' contributions}

AN brought the original idea, was involved in the proposal writing, designed the study, and participated in all the implementation stages of the project. $\mathrm{AN}, \mathrm{RH}$ also analyzed data and wrote the initial version of the manuscript. $\mathrm{AN}, \mathrm{RH}$, participated in the conception of the original idea and were involved in proposal 
writing. AN, and SM were involved with data analysis. SM checked and reran data analyses and extensively rewrote the manuscript prior to submission. $\mathrm{AN}, \mathrm{RH}$, and $\mathrm{SM}$ critically revised the manuscript for important intellectual content. All the authors read and approved the final version of the manuscript.

\section{Acknowledgements}

We thank Lemlem Karl Hospital Maichew especially COVID-19 treatment center for their compassionate cooperation and provision accurate information during data collection and also for facilitating the study.

\section{Author details}

${ }^{1}$ Department of Health Management Information System, AlamataGeneral Hospital, Alamata, Tigray, Ethiopia. ${ }^{2}$ Department of Health Management Information System, Lemlem Karl Hospital, Maichew, Tigray, Ethiopia. ${ }^{3}$ Departments of Statistics, College of Natural and Computational Sciences, Mekelle University, Mekelle, Ethiopia.

\section{Supplementary information}

The online version contains supplementary material available.

\section{Additional file1.}

\section{References}

1. Greenhalgh T, Schmid MB, Czypionka T, Bassler D, Gruer L. Face masks for the public during the covid-19 crisis. BMJ. 2020;369:m1435,. https://doi.org/10.1136/bmj.m1435.

2. Lai CC, Wang CY, Wang YH, Hsueh SC, Ko WC, Hsueh PR. Global epidemiology of coronavirus disease 2019 (COVID-19): disease incidence, daily cumulative index, mortality, and their association with country healthcare resources and economic status. Int J Antimicrob Agents. 2020;55:105946. https://doi.org/10.1016/j.ijantimicag.2020.105946.

3. WHO. Coronavirus disease 2019 (COVID-19) Situation Report - 195. WHO; 2020.

4. Worldometersinfo Coronavirus Update (Live) Worldometer 2021.

5. Suleiman A, Bsisu I, Guzu H, et al. Preparedness of Frontline Doctors in Jordan Healthcare Facilities to COVID-19 Outbreak. Int J Environ Res Public Health. 2020;17:3181.

6. Powell-Jackson T, King JJC, Makungu C, et al. Infection prevention and control compliance in Tanzanian outpatient facilities: a cross-sectional study with implications for the control of COVID-19. The Lancet Global Health. 2020;8:e780.

7. Saint S, Ratz D. Improving Hand Hygiene Adherence in Healthcare Workers Before Patient Contact: A Multimodal Intervention in Four Tertiary Care Hospitals in Japan. Epub ahead of print 1 May 2020. DOI: 10.12788/jhm.3446. Houghton C, Meskell P, Delaney H, et al. Barriers and facilitators to healthcare workers' adherence with infection prevention and control (IPC) guidelines for respiratory 
infectious diseases: a rapid qualitative evidence synthesis. Cochrane Database Syst Rev. 2020; 4: CD013582.

8. Gershon RR, Zhi Q, Chin AF, et al. Adherence to Emergency Public Health Measures for Bioevents: Review of US Studies. Disaster Med Public Health Prep. 2018;12:528-35.

9. Ajilore K, Atakiti I, Onyenankeya K. College students' knowledge, attitudes and adherence to public service announcements on Ebola in Nigeria: Suggestions for improving future Ebola prevention education programmes. Health Education Journal. 2017;76(6):648-60. Epub 2017/10/01.

10. Tachfouti N, Slama K, Berraho M, Nejjari C. The impact of knowledge and attitudes on adherence to tuberculosis treatment: a case-control study in a Moroccan region. The Pan African medical journal. 2012;12:52. Epub 2012/09/01.

11. AtkureDefar GebeyawMolla. SaroAbdella, et al. Knowledge, Practice and associated factors towards the Prevention of COVID-19 among high-risk groups: A cross-sectional study in Addis Ababa, Ethiopia. PLoS ONE 15(10): e0239254.https://doi.org/10.1371/journal.pone.0239254.

12. Ferdous MZ, Islam MS, Sikder MT, Mosaddek ASM, Zegarra- Valdivia JA, Gozal D. (2020) Knowledge, attitude, and practice regarding COVID-19 outbreak in Bangladesh: An online-based cross-sectional study.PLoSONE15(10): e0239254.https://doi.org/10.1371/journal. pone.0239254.

13. Erfani A, Shahriarirad R, Ranjbar K, Mirahmadizadeh A, Moghadami M. Knowledge. Attitude and Practice toward the Novel Coronavirus (COVID-19) Outbreak: A Population-Based Survey in Iran. Bull World Heal Organ. 2020. https://www.who.int/bulletin/online_first/20-256651.pdf.

14. Zhong B, Luo W, Li H, Zhang Q, Liu X, Li W, et al. Knowledge, attitudes, and practices towards COVID19 among Chinese residents during the rapid rise period of the COVID-19 outbreak: a quick online cross-sectional survey. Int J Biol Sci. 2020;16(10):1745-52.

15. Srichan P, Apidechkul T, Tamornpark R, Yeemard F, Khunthason S, Kitchanapaiboon S, et al. Knowledge, attitude and preparedness to respond to the 2019 novel coronavirus (COVID-19) among the bordered population of northern Thailand in the early period of the outbreak: a cross-sectional study. 2020. https://papers.ssrn.com/sol3/papers.cfm?abstract_id=3546046.

16. Zhong BL, Luo W, Li HM, et al. Knowledge, attitudes, and practices towards COVID-19 among Chinese residents during the rapid rise period of the COVID-19 outbreak: a quick online cross -sectional survey. Int J Biol Sci. 2020;16(10):1745-52. https://doi.org/10.7150/ijbs.45221PMID:32226294.

17. Srichan P, Apidechkul T, Tamornpark R, Yeemard F, Khunthason S, Kitchanapaiboon S, et al. Knowledge, Attitude and Preparedness to Respond to the 2019 Novel Coronavirus (COVID-19) Among the Bordered Population of Northern Thailand in the Early Period of the Outbreak: A Cross-Sectional Study. SSRNElectronicJournal.2020. https://doi.org/10.2139/ssrn.3546046.

18. .Saqlain M. MunirMM,UrRehmanS,GulzarA,NazS,AhmedZ,etal.Knowledge, attitude, practice and perceived barriers among healthcare professionals regarding COVID-19: A Cross-sectional survey From Pakistan.medRxiv,2020. https://doi.org/10.1101/2020.04.13.20063198.

19. Erfani A, Shahriarirad R, Ranjbar K, Mirahmadizadeh A, Moghadami M. Knowledge. Attitude and Practice toward the Novel Coronavirus (COVID-19) Outbreak: A Population-Based Survey in Iran. Bull 
World Heal Organ. 2020. https://www.who.int/bulletin/online_first/20-256651.

\section{Tables}

Table-1: Socio-demographic characteristics COVID-19 Positive patients at Southern Tigray, North Ethiopia. 


\begin{tabular}{|c|c|c|c|}
\hline characteristics & Categories & Frequency (n) & Percent (\%) \\
\hline \multirow[t]{2}{*}{ Sex } & Male & 106 & $62.4 \%$ \\
\hline & Female & 64 & $37.6 \%$ \\
\hline \multirow[t]{4}{*}{ Age in years } & Less than 18 & 07 & $4.1 \%$ \\
\hline & $18-44$ & 150 & $88.2 \%$ \\
\hline & $45-64$ & 08 & $4.7 \%$ \\
\hline & $65+$ & 05 & $2.9 \%$ \\
\hline \multirow[t]{4}{*}{ Religion } & Orthodox & 148 & $87.1 \%$ \\
\hline & Muslim & 13 & $7.6 \%$ \\
\hline & Protestant & 08 & $4.7 \%$ \\
\hline & Others & 01 & $0.6 \%$ \\
\hline \multirow[t]{4}{*}{ Income in ETB } & Less than or equal 1000 & 20 & $11.8 \%$ \\
\hline & $1001-3000$ & 41 & $24.1 \%$ \\
\hline & $3001-10,000$ & 72 & $42.4 \%$ \\
\hline & $>10,000$ & 37 & $21.8 \%$ \\
\hline \multirow[t]{3}{*}{ Education Qualification } & Diploma & 92 & $54.1 \%$ \\
\hline & Degree & 74 & $43.5 \%$ \\
\hline & Masters and Above & 04 & $2.4 \%$ \\
\hline \multirow[t]{8}{*}{ Occupation } & Health care professional & 68 & $40 \%$ \\
\hline & Driver & 08 & $4.7 \%$ \\
\hline & Student & 12 & $7.1 \%$ \\
\hline & Grocery worker & 14 & $8.2 \%$ \\
\hline & Banker & 12 & $7.1 \%$ \\
\hline & Governmental employee & 18 & $10.6 \%$ \\
\hline & Business man & 17 & $10 \%$ \\
\hline & Other & 21 & $12.4 \%$ \\
\hline
\end{tabular}

Table: 2- Magnitude of knowledge, attitude, and practice of preventing COVID-19 positive patients at Southern Tigray Ethiopia, 2020. 


\begin{tabular}{|c|c|c|c|}
\hline characteristics & Categories & $\begin{array}{l}\text { Frequency } \\
(\mathrm{n})\end{array}$ & $\begin{array}{l}\text { Percent } \\
(\%)\end{array}$ \\
\hline \multirow{5}{*}{$\begin{array}{l}\text { Knowledge on the transmission } \\
\text { mode of COVID-19 }\end{array}$} & Direct contact with COVID-19 patient & 130 & $76.5 \%$ \\
\hline & Breathing & 118 & $69.4 \%$ \\
\hline & Coughing/sneezing & 113 & $66.5 \%$ \\
\hline & Eating and drinking & 70 & $41.2 \%$ \\
\hline & Others & 20 & $11.8 \%$ \\
\hline \multirow{4}{*}{$\begin{array}{l}\text { Knowledge on the prevention } \\
\text { mode of COVID-19 }\end{array}$} & Maintain Social distance & 143 & $84.1 \%$ \\
\hline & Hand washing frequently & 136 & $80 \%$ \\
\hline & Use face mask in crowded place & 131 & $77.1 \%$ \\
\hline & Maintain Isolation/quarantine & 67 & $39.4 \%$ \\
\hline \multirow[t]{6}{*}{$\begin{array}{l}\text { Attitude on the prevention mode } \\
\text { of COVID- } 19\end{array}$} & $\begin{array}{l}\text { Health education can play an important } \\
\text { role }\end{array}$ & 98 & $57.6 \%$ \\
\hline & It can he treated at home & 135 & $79.4 \%$ \\
\hline & COVID-19 is a nreventable disease & 143 & $84.1 \%$ \\
\hline & & 151 & $88.8 \%$ \\
\hline & $\begin{array}{l}\text { It Is Important to use a tacemask in } \\
\text { crowded place. }\end{array}$ & 138 & $81.2 \%$ \\
\hline & $\begin{array}{l}\text { It is important to wash hands and face } \\
\text { after coming outsides. }\end{array}$ & & \\
\hline \multirow{8}{*}{$\begin{array}{l}\text { Practice on the prevention mode } \\
\text { of COVID- } 19\end{array}$} & Obey governmental rules & 60 & $35.3 \%$ \\
\hline & Hanker chips during coughing/sneezing & 137 & $80.6 \%$ \\
\hline & Eat healthy food focusing on outbreak & 56 & $32.9 \%$ \\
\hline & $\begin{array}{l}\text { Maintain healthy life style focusing on } \\
\text { outbreak }\end{array}$ & 115 & $67.9 \%$ \\
\hline & Avoid touching face and eves & 118 & $69.4 \%$ \\
\hline & Maintain social distance & 151 & $88.8 \%$ \\
\hline & Wash hands frequentlv & 138 & $81.2 \%$ \\
\hline & Use a face mask in crowded place & 55 & $32.4 \%$ \\
\hline
\end{tabular}

Table3. Crude and Adjusted Odds ratio for determinant factors associated with knowledge for preventing COVID-19 positive patients at Southern Tigray Ethiopia, 2020. 


\section{Less More \\ accurate accurate}

\section{Income in ETB}

$\begin{array}{lllll}<=1,000 & 08 & 12 & 0.41(0.133, & 0.11(0.016, \\ 1,001-3,000 & 11 & 30 & 1.24)^{*} & 0.73)^{* *} \\ 3,001-10,000 & 17 & 55 & 0.22(0.09, & 0.58(0.09,3.75) \\ >10,000 & 23 & 14 & 0.19(0.08, & 0.19(0.34, \\ & & & 0.44)^{\star * \star} & 0.92) * \star \\ & & 1\end{array}$

\section{Occupation}

$\mathrm{HCW}$

02

68

0.007(0.001,

0.006(0.001,

Driver

03

08

Student

07

12

$0.14(0.023$, $0.85)$ **

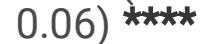

Grocery worker

08

14

$0.33(0.068,1.6)$ *

$0.08(0.003,1.7)$ *

Business man

07

17

$0.31(0.069,1.4)$ *

0.57(0.065,

Banker

04

12

$0.17(0.038$,

Governmental employee

11

18

Others

17

21

$0.71) * *$

$5.02)$ *

$0.11(0.01,1.3)$ *

$0.12(0.023$,
$0.6) * *$

$0.17(0.022$

$0.1 .3)$ *

$0.37(0.087,1.6)$ *

$0.23(0.03,2.1)$ * 1

$0.24(0.03,1.9)$ * 1

\section{Knowledge of transmission}

Good

08

Poor

51

79

0.06(0.03,

$0.15) * \star * \star$

$0.06(0.018,0.19)$

32

1

1

\section{Experience of respiratory}

illness

Symptomatic

Asymptomatic

03

56

56

$0.28(0.078$ $0.98)$ **

$0.19(0.023,1.6)$ *

93

1 
conditions

Yes

01

14

$0.12(0.015$,

97

58 $0.93)$ **

$0.06(0.006$,

No

1

1

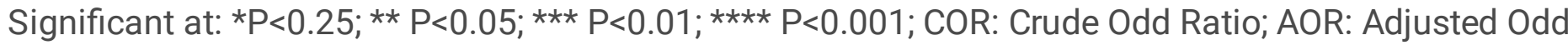
Ratio; Cl: Confidence Interval; $1=$ Reference category.

Table4. Crude and Adjusted Odds ratio for determinant factors associated with attitude for preventing COVID-19 positive patients at Southern Tigray Ethiopia, 2020. 
Variables

Attitude

$\operatorname{COR}(95 \% \mathrm{Cl})$

AOR $(95 \% \mathrm{Cl})$

\section{Less More \\ positive positive}

Income in ETB

$<=1,000$

12

08

$1.4(0.47,4.3)$

$2.5(0.54,11.5)$

$1,001-3,000$

11

30

0.35(0.14,

$0.6(0.15,2.5)$

$3,001-10,000$

21

51

$0.89)$ **

$>10,000$

19

18

0.39(0.17,

$0.89)$ **

$1.0(0.28,3.7)$

1

\section{Knowledge of transmission}

Good

12

75

$0.1(0.05$

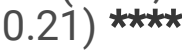

0.05(0.016,

51

32

1

1

Washing hands and face after coming outsides.

Agree

Undecided

44

94

07

Disagree

04

12

09

3.7(1.04,

13.4) **

$0.21(0.05$,

$0.84)^{* *}$

2.8(1.12,

$7.3) * \star$

1
$2.6(0.28,4.4)$

1

\section{Treated at home.}

$\begin{array}{lllll}\text { Agree } & 25 & 73 & 0.35(0.14, & 0.1(0.028, \\ \text { Undecided } & 05 & 14 & 0.9)^{\star *} & 0.32) * \star \star * \\ \text { Disagree } & 33 & 20 & 1.3(0.29,5.9) & \begin{array}{l}0.12(0.03,0.58) \\ * \star *\end{array} \\ & & & 1 & 1\end{array}$

Use a facemask in crowded place.

Agree

Undecided

56

95

$0.3(0.07$

$1.23)$ *

0.016(0.001,

Disagree

01

09

06

03

$0.06(0.05$

$0.67)$ **

$0.57(0.07,4.6)$ 
Significant at: $* \mathrm{P}<0.25$; $* \star \mathrm{P}<0.05 ; * \star \star \mathrm{P}<0.01 ; * \star \star \star \mathrm{P}<0.001$; COR: Crude Odd Ratio; AOR: Adjusted Odd Ratio; Cl: Confidence Interval; $1=$ Reference category.

Table5. Crude and Adjusted Odds ratio for determinant factors associated with practice for preventing COVID-19 positive patients at Southern Tigray Ethiopia, 2020. 
Variables

Practice

$\operatorname{COR}(95 \% \mathrm{Cl})$

AOR $(95 \% \mathrm{Cl})$

\section{Less More \\ frequent frequent}

Income in ETB

$<=1,000$

08

12

1.12(0.35, 3.6)

$0.74(0.125,4.3)$

$1,001-3,000$

11

30

0.46(0.18,

$0.71(0.13,4.0)$

$3,001-10,000$

17

55

1.1)

$0.46(0.11,2.0)$

$>10,000$

23

14

0.34(0.15,

$0.79)$ **

1

1

Knowledge for transmission

Good

33

54

$0.3(0.16$

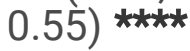

56

27

1

$1.2(0.45,3.2)$

Poor

02

19

0.08(0.017,

$0.33)$

Symptomatic

87

62

1

1

Under line co-morbidity and conditions

Yes

No

11

78
04

77
$2.7(0.83$

$8.9)$ **

1
1
$0.043(0.007$
$0.27) * * *$

Knowledge for preventing COVID-19

More accurate

Less accurate

35

76

0.04(0.016,

0.05(0.012,

54

05

$0.12) * \star \star *$

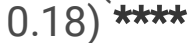

$2.7(0.74,9.7)$ *

1 
51

12
$0.1(0.06$
$0.32(0.1$,

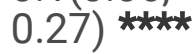
$1.02)$ **

1

1

Maintain social distance

$\begin{array}{lllll}\text { Yes } & 02 & 58 & 0.006(0.001, & 0.017(0.001 \\ \text { Sometimes } & 55 & 17 & 0.03)^{* *} & 0.21)^{* * * *} \\ \text { No } & & & 0.61(0.22,1.7) & 0.37(0.082 \\ & 32 & 06 & 1 & 1.67)^{*} \\ & & & & 1\end{array}$

Obeying governmental rules related to COVID-19

Yes

Sometimes

03

57

0.005(0.001,

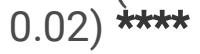
0.095(0.009, 41

20

No

04

$0.18(0.06$,
$0.58) * * \star$ $1.03)^{* \star}$

1

$0.039(0.007$,

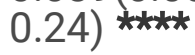

1

Eat healthy food focusing on outbreak

Yes

No

01

55

0.005(0.001, $0.04) * * * *$

$0.12(0.009$,

88

26

1

1

Maintain a healthy lifestyle focusing

on outbreak

Yes

Sometimes

67

$0.14(0.05$,

$0.4)$

$0.2(0.04$

16

09

No

25

05

$0.36(0.1,1.3)$ *

$0.7(0.14,3.7)$

1

1

Use tissues or hanker chips during

coughing/sneezing

Yes

Sometimes

59

No
11

19
78

02

01
0.04(0.005, $0.3)$

$0.29(0.02,3.6)$

$0.09(0.008$

$1.1) * *$

$0.31(0.012,8.1)$ 


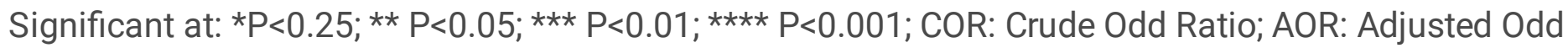
Ratio; Cl: Confidence Interval; $1=$ Reference category.

\section{Supplementary}

Additional File 1 is not available with this version.

\section{Figures}

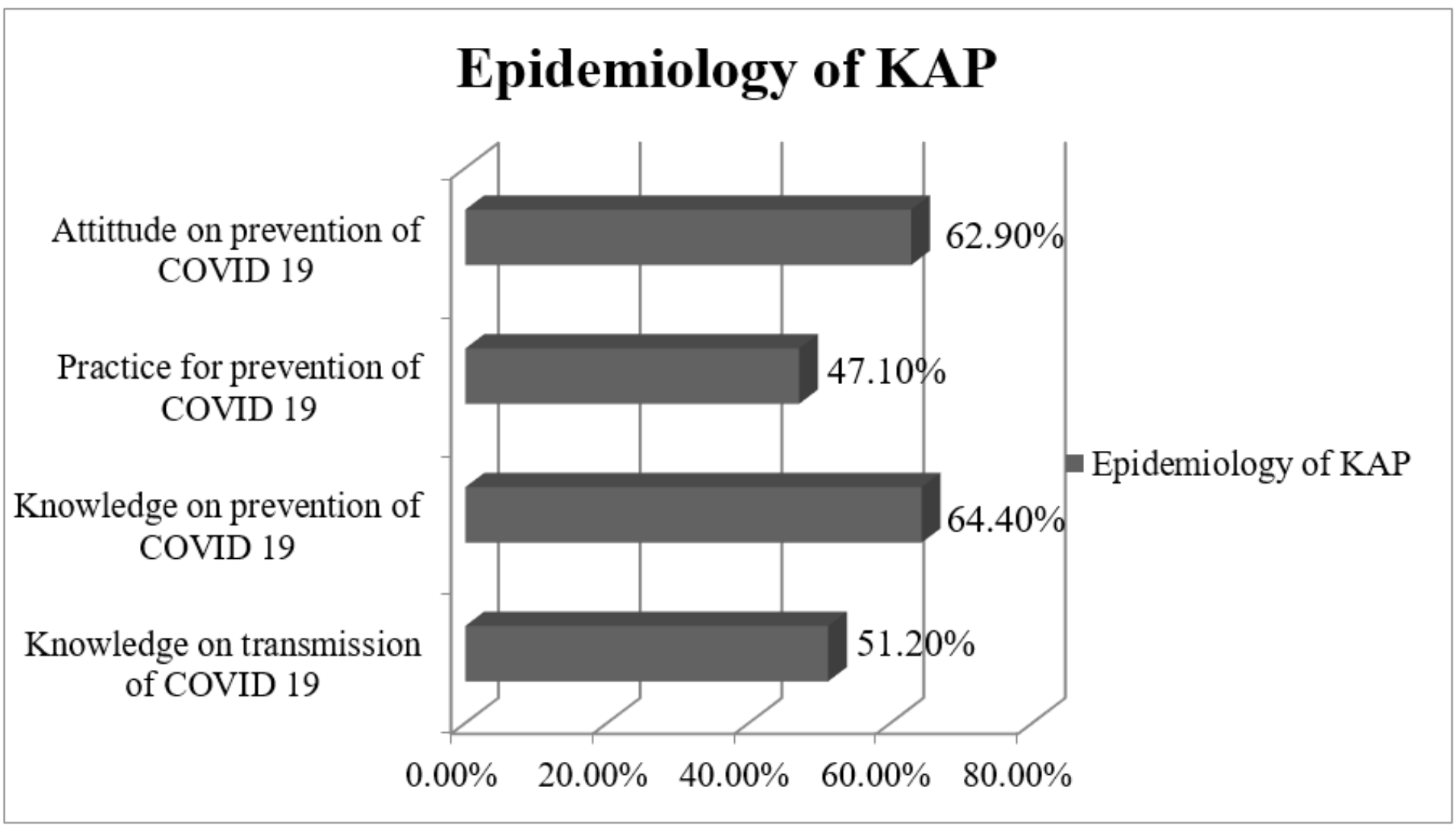

Figure 1

Epidemiology of knowledge on the transmission, prevention, attitude and practice of precautionary measure of COVID-19 